\title{
Enseñar y aprender, la poética de la presencia en un aula de primaria: un estudio narrativo
}

Resumo Este artículo es una composición narrativa en torno a la vida que se va sucediendo en un aula de primaria. En la composición del relato se ha buscado ir elaborando el sentido de la escuela como posibilidad de encuentro y de relación. Un pensar la escuela como lugar para ser y como experiencia de relación con la alteridad. El relato es el fruto de un ir acompañando a esta maestra en su quehacer cotidiano en la escuela durante dos cursos escolares. Un proceso de acompañar y narrar que me ha ayudado a reconocer y nombrar las cualidades educativas, las disposiciones subjetivas y los saberes con los que esta maestra va sosteniendo y dando sentido a su práctica pedagógica. Dicho trabajo se enmarca en el desarrollo de dos proyectos de investigación cuyo foco de estudio es indagar los saberes experienciales con los que docentes, de educación infantil y primaria, sostienen sus prácticas educativas para explorar su valor formativo y sus posibles implicaciones para la formación inicial. Nuestra finalidad no es hacer un inventario de buenas prácticas sino un ir aprendiendo de y con docentes para procurar vivificar el conocimiento pedagógico. Para transformar nuestras prácticas en la formación inicial del profesorado.

PALAVRAS-CHAVE: Indagación narrativa; Saber de la experiencia; Composición curricular. 


\title{
Teaching and learning, the poetics of presence in a primary classroom: a narrative study
}

\begin{abstract}
This article is a narrative composition about life that takes place in a primary classroom. The composition of the story has sought to develop the sense of school as a possibility of encounter and relationship. Thinking school as a place to be and as an experience of relationship with otherness. The story is the result of accompanying this teacher in her daily work at school during two school years. A process of accompanying and narrating that has helped us recognize and name educational qualities, subjective dispositions and knowledge that hold and give meaning to her pedagogical practice. This work is part of the development of two research projects whose study focus is to investigate the experience knowledge with which pre-school and primary education teachers support their educational practices, in order to explore its formative value and its potential implications for teacher education. Our purpose is not to make an inventory of good practices but to learn from and with teachers to try to vivify the pedagogical knowledge. To transform our practices in the teacher education.
\end{abstract}

KEYWORDS: Narrative inquiry; Experience knowledge; Curricular composition.

\section{Entrar a la escuela}

E1 cuerpo puede volverse hablante, pensante, soñante, imagínate. Todo el tiempo siente algo. Siente todo lo que es corporal. Siente las pieles y las piedras, los metales, las hierbas, las aguas y las llamas. No para de sentir.

Jean-Luc Nancy (2006, p.15)

Son las nueve de la mañana. Suena la música de Bebe ${ }^{1}$ mientras el conserje abre las puertas de la escuela. Las niñas y los niños juegan unos minutos en el patio con la gente de clase antes de entrar. No se hacen filas, aunque tampoco se entra de cualquier manera al edificio, no hay carreras ni desorden. Van entrando de dos en dos, de tres en tres, en grupos pequeños, en solitario. Al cruzar la puerta hay alguien que los recibe. Que los saluda, que les abraza o les besa. Que les sonríe, que les hace un guiño, que les adereza la mochila o la chaqueta o el pelo. Alguien que les da la bienvenida. Que les espera y les ayuda a acompasar su marcha, a modular su voces, a calmar su excitación ${ }^{2}$.

Recreando esta escena, siento que cobran fuerza las palabras de Jean-Luc Nancy (2006). Palabras que recuerdan la centralidad del cuerpo como sede experiencia, como lugar de relación. Que conectan con la cadencia de esta escena. La música, el movimiento, los gestos. Me recuerdan que aprendemos experimentando el mundo, dejándonos atravesar, alterar y transformar por él, (Bárcena y Mélich, 2000). Que es en el sentir, sintiendo, como vamos tomando conciencia del mundo. Porque el cuerpo 
no para de sentir. $Y$ en esta escena, la música que suena nos lleva a un sentir en un movimiento hacia el encuentro, hacia la búsqueda del otro, hacia lo otro que nos espera. Se puede decir que sentir es ya una inteligencia del mundo que permite que el mundo vaya tramándose en cada cuerpo, (Le Breton, 2010). En cada quien. En un alguien. Y a la vez, convertirnos en ese alguien, en ese quien. Las emociones y los sentimientos no son, o no son solo, procesos fisiológicos: son, primeramente, relaciones y significaciones, (Le Breton, 2010). Es decir, los gestos que alimentan nuestra relación con el mundo y nos dan presencia, remiten a una cultura corporal que les da sentido. Una cultura afectiva que acoge al sujeto y donde éste se realiza. Se va realizando, en un constante ir aprendiendo y desaprendiendo. Porque el ser humano siempre aprende y desaprende, no queda determinado ni encerrado por su historia. Siempre es posible abrirse a otras experiencias, a otros aprendizajes.

Me pregunto cómo puede nutrir la escuela esa apertura. Qué formas de vivir y ser ofrece. ¿Qué cartografía de la escuela, esta escuela ${ }^{3}$, puede recorrerse explorando la experiencia sensible, corporal, que en ella se vive y se recrea? ¿Qué experiencias educativas o qué práctica docente o qué implicaciones curriculares puede iluminar este recorrido? ¿Cuánto de ello, de estas distintas dimensiones, podría reconocer y profundizar si presto atención a la experiencia corporal?

\section{Cuidar el encuentro}

Lo que voy observando y lo que me va envolviendo en este tiempo en la escuela, es un modo de procurar y cuidar el encuentro. Cuidar, afirma Nel Noddings (2005), es una forma de relación. No se trata de un atributo o de un rasgo de personalidad, sino de la propia relación y el sentido que se va elaborando a ese estar en relación. Cuidar es un modo de entrar y un modo de estar en relación. Vuelvo a la escena anterior y recupero algunos de los gestos más repetidos: la sonrisa, el abrazo, la mirada cómplice, la mueca, ese modo de revolotear el cabello, de poner la mano en el hombro o de dar la mano, de atar las zapatillas, de recolocar las mochilas, ... Son todos gestos pequeños, amorosos. Gestos de apertura que ponen el acento en el cuidado, que acercan el sentir, el mirar, el conmoverse y dejarse afectar con la presencia del otro. Son todos gestos que señalan una disposición, que nos disponen a recibir, a acoger, a alojar. Y que nos llevan a actuar en ese sentido que marca la disposición. Es decir, a un actuar con cuidado, con amorosidad. A un actuar desde el cuidado, prestando atención, con respeto. A un actuar para el cuidado, con tacto, con saber, con calma. Y lo que da profundidad a esa práctica del cuidado es la profundidad y el deseo de encontrarse con el otro. De hacer crecer en sí y en el otro la sensibilidad que, dice Emma Quiles-Fernández (2016), no se refiere únicamente a la capacidad de percepción sino también, al modo en que uno aprende a dar acogida y sentido a lo que percibe.

Estos gestos que invitan a mirarse, a sentirse, a reconocerse, a estar cerca, a conversar son pasaje de encuentro. Un encuentro vivo, y siempre inaugural, que precisa de estos gestos relacionales. ¿Siempre inaugural el encuentro? Me vuelvo a preguntar, pues Lo cierto es que la escena se repite a lo largo de la jornada escolar: la entrada matutina, la entrada tras el recreo, la entrada de la tarde. Con una música u otra, el ritual se repite. ¿Qué tiene de inaugural, entonces?. El propio sentido del “encuentro". De la palabra, de la idea, de la práctica. 
La experiencia de encontrarse pasa inadvertida en el lenguaje escolar, o más concretamente, en el modo de hablar de (y sobre) la escuela. Quizás porque se da por supuesto el encuentro. El hecho de que niñas, niños y adultos van a coincidir en un espacio. Lo que se advierte de esa coincidencia es si se da el entendimiento o el conflicto; y qué cuestiones didácticas, normativas y/o sociales están implicadas ahí. Sin embargo, conviene indagar, redefinir, el significado y el sentido que, como docentes, queremos darle al encuentro. Atreverse a pensarlo, a vivificarlo y nutrirlo desde el límite del dispositivo escolar. El encuentro supone la experiencia de construirnos colectivamente, de armar comunidad, de significar el "estar juntos", ampliando las relaciones con el mundo (Punta, 2013). En un presente impaciente como el que vivimos, marcado por un exceso de predictibilidad, de rigidez burocrática, de rapidez... quizás, demorarse en significar educativamente el encuentro sea una posibilidad de interrumpir esa inercia. Un modo de resguardar, de custodiar y de atender lo común y la alteridad. De cuidar el entramado humano en la escuela a partir de un dejarse afectar de la distancia entre lo propio y lo ajeno ${ }^{4}$. Alberto entra un lunes por la mañana con una medalla de oro colgada al cuello y dice: "Inma, ayer gané en el campeonato de taekwondo". Lola vuelve de casa de su abuela que le ha preparado su comida preferida, su sonrisa la delata y Joan, cómplice, le pregunta: “¿has comido en casa de la abuela?”. Acaba el recreo, Marta y sus tres amigas me muestran el insecto que han recogido del patio. Encontrarse posibilita el conversar. Contar lo que nos pasa (o nos ha pasado), compartirlo, recrearlo, en definitiva, ampliar las relaciones con los otros, con el mundo. Cuidar el encuentro custodiando la sorpresa, la novedad, la emoción que lleva con él, transforma la indiferencia de lo rutinario en prácticas que estimulan otras formas de mirarnos, de hablarnos, de pensarnos. Formas que alimentan una vida en común, que nutren el pasaje entre lo común y la comunidad.

Cuidar el encuentro para nacer escuela (Punta, 2013). Nutrir ese pasaje entre lo propio y lo ajeno, lo común y la comunidad. Entre la enseñanza y el aprendizaje, entre el ser y el saber, entre el vivir y el pensar. Y darle, envoltura narrativa (López, 2016). Darle cuerpo, voz, ternura a esa trama escolar que constituye relaciones, historias, aprendizajes.

\section{Habitar la escuela}

La escuela se encuentra al final del pueblo. No hay edificios alrededor, pero no parece apartada, aislada. La rodea la huerta. Campos de huerta (naranjos, higueras, cultivo...) que se han salvado de la salvaje especulación del suelo vivida en las últimas décadas. Anticipa la llegada a la escuela un pequeño terreno de pinos que le da un tono amable de cobijo y de resguardo. Un tono que se extiende hasta ese patio amplio y agradable que contiene al edificio escolar. Un patio con canchas para el futbol, pero también mucho otro espacio para otros juegos y otros modos de vivirlo. Hay tierra, y bancos, y árboles y una fuente, y las formas de estar y de jugar en el patio son ricas y diversas. Sí, hay una amabilidad intrínseca en el entorno de la escuela que anticipa cierto bienestar.

El edificio, sin embargo, coincide mucho más con el imaginario de escuela que tenemos más incorporada, que nos es más reconocible. Un edificio con aulas se- 
paradas, no demasiado amplias, distribuidas entre dos pisos más la planta baja. Con pasillos y mobiliario estándar. El edificio, nos decía Inma a mis estudiantes y a mí hace poco, invita más a padecerlo que a disfrutarlo. Invita a padecerlo su arquitectura, pues se impone de tal modo, que cuesta pensar otros modos de acomodar y utilizar sus espacios $^{5}$. Sin embargo, para quien viene de fuera, es posible percibir muchos detalles en el interior del edificio que van mostrando un modo de habitarlo, de singularizarlo, de darle vida, de recrearlo. Un modo, quizás, de ir preparando el encuentro, trayendo a él una y otra vez, muestras de la vida que se comparten en la escuela y muestras de la vida que se suceden fuera de ella que merecen ser cultivadas o cuestionadas, si es que no nos humanizan. El enorme frontal del hall es un lugar privilegiado para ello. Siempre en cambio, va mostrando señales de vida, de reflexión, de esperanza, de solidaridad, de inquietud, de gratitud, de impacto... Así, he ido encontrando en él referencias al atentado al semanario francés Charlie Hebdo. Denuncias a diferentes formas de violencia, entre ellas la violencia machista. $\mathrm{O}$ muchas celebraciones a partir de las cuales se recopilan, se significan y se muestran saberes y prácticas que sostienen la vida, que hacen cultura $\mathrm{y}$ de las que podemos aprender.

Es interesante percibir esta interrupción entre lo que hace sentir el entorno de la escuela y el edificio escolar. Hay un vacío (simbólico) en ese tono de bienestar, y a la vez una necesidad de continuidad. $Y$ es aquí, en este hiato donde quisiera situar la idea (y la imagen) de "habitar la escuela", pues remite a un "estar presentes en ella", a un hacerse presente. Lo que significa responderse a la pregunta de cómo se quiere vivir en ella. Qué vida se le quiere dar y cómo se puede vivificar para que el bienestar pueda ser posible también en este edificio que, de entrada, se siente más inhóspito y menos agradable y acogedor que el entorno que lo envuelve.

Hacer habitable la escuela implica interrogar distintos aspectos de lo escolar que son condiciones y condicionantes de la experiencia de crecer, aprender y enseñar. Que remiten siempre a la relación entre lo personal y lo social, entre el mundo interior y exterior, entre lo propio y lo común. Para Inma, hacer lugar para darle lugar a este "entre", implica poner atención en la mediación educativa. Ella habla de crear vínculos. Con el espacio, con las criaturas, con las familias, con el saber, entre docentes... Vínculos que favorezcan que los aspectos del vivir con los que nos relacionamos estando en la escuela, puedan ser significados y re-significados. Que motiven el bienestar, que favorezcan una escuela bonita, humana y habitable.

Sentir la escuela con confianza. Sentirla como un lugar seguro para ser, son premisas necesarias para habitarla. Significa que las experiencias de niños y de adultos tienen cabida en la escuela. Que no dejamos nada fuera cuando entramos en la escuela. Que en la escuela cabe nuestra alegría pero también el dolor cuando lo tenemos. O la fatiga. O la inseguridad. O una buena idea. Pero también la del otro. Para hacer habitable la escuela ha de ser plausible el disenso, la divergencia, la diferencia. Cuidar el encuentro implica aceptar que a ratos puede darse el desencuentro, pero no la indiferencia. Tampoco el anonimato. Sobre ello, escribe Joan Carles Mèlich (2005, p.17), "desde el momento en que habitamos el mundo vivimos no solamente con los otros, sino frente a ellos, frente a cada uno de ellos, frente al que se me presenta como rostro, como único, como portador de un nombre. Este otro singular que me apela o 
me encara me recuerda que nunca estoy completamente solo en la configuración del sentido, en la invención del sentido". Habitar la escuela implica un ir elaborando cotidianamente, para sí y los otros, aquello que "nos vale" la pena cuidar.

Recorriendo la escuela pueden observarse signos de esas relaciones que se cuidan. Los signos, a veces, sólo son gestos, miradas, cadencias. Otras veces los signos son huellas que se van dejando, actividades que se componen con el trabajo de todas las aulas, celebraciones que se tienen muy presentes.

\section{Deambular el currículum}

Inma me pasa el horario de su clase de tercero. Estudio el horario para encontrar momentos largos en los que hacer el acompañamiento. Me sorprende, ha sido fácil encontrarlos. No es un horario hecho de ratitos. No da la sensación de demasiado lleno ni demasiado acelerado ni demasiado disperso. En la escuela han procurado, me explica Inma, agrupar los tiempos de las asignaturas ${ }^{6}$. La mañana del miércoles, por ejemplo, las dos primeras sesiones era matemáticas y las dos siguientes de castellano. $\mathrm{O}$ la tarde del martes era para plástica. Esta combinación del horario permite desarrollar dinámicas más diversas, enriquecedoras y tranquilas. Que no ahogan el movimiento de la curiosidad y el asombro de las criaturas. Lo he podido percibir y vivir con mucha intensidad en este tiempo de acompañamiento; la rutina diaria no ha cedido sentido a lo rutinario. Y es que, al ampliar el tiempo de las sesiones se abre la posibilidad de cuidar los momentos: para hablar, para escuchar, para concentrarse, para respirar, para trabajar en grupo, para reír, para ayudar al otro... Por otra parte, en todo este tiempo de acompañamiento, el horario ha ido señalando "en qué estamos" pero no ha determinado lo que me puedo encontrar ni cómo se va a suceder. También, porque no hay un libro de texto por asignatura que pauta la actividad y el recorrido a seguir.

"Aquí no hacemos deberes normales", me dice Joel el primer día que entro al aula. No hacer deberes normales quiere decir que las maestras de este nivel han decidido no poner tareas para completar, o acabar, las actividades de las materias. Tareas que son deberes, deberes que son obligaciones... para casa. Para Joel informarme de que no hacían deberes normales era tan importante como hacerme saber aquello otro que podían hacer en casa, que no tenía que ver con la "obligación" pero sí con el estudio: leer, dibujar, experimates, manualidades, búsquedas de información, poesía, collage... Posibilidades, otras, que las maestras han ido proponiendo y que las criaturas han ido acogiendo e implicándose en ellas.

Para Inma saber es un placer y aprender, tiene que ver con el placer, también. Atender este principio supone generar experiencias en relación con el saber que den medida vital a las criaturas de que les ayudan a crecer. Lo que significa romper con esa perspectiva pedagógica que pospone los sentidos personales de lo que se va viviendo, aprendiendo y adquiriendo como saber para un futuro, para un momento posterior que ya no es escolar (Contreras, 2007), o como respuestas a las demandas que se desprenden de etapas escolares posteriores. Romper, invita Penny Ritscher (2002), con esa perspectiva que pone el énfasis en el "desde" y "para" el mañana. Se trata, más bien, de generar una forma personal de relación con el saber que facilite conectar con las 
inquietudes de las criaturas y que les permita avanzar en su interpretación del mundo. Lo que implica, como maestra, buscar formas de organizar la experiencia de enseñanza y de aprendizaje desde situaciones que mueven hacia la interrogación y la búsqueda, en las que sea posible vincularse a partir de las posibilidades, las necesidades y las emociones de cada quien. Me conecto, escribe Inma Coscolla (2016, p.8), "con el arte de propiciar que una criatura aprenda y crezca en la lectura, en la escritura, en el arte, en el razonamiento, en la investigación, en la reflexión, en sus relaciones (...). Procuro ser una mediación con el saber que propicie un vínculo con él, que no les aporte tensiones gratuitas, retos, competiciones, sobrecargas".

Lo que voy encontrando en este aula es un esquema de trabajo que no pone el énfasis en la asimilación (pasiva) de contenidos sino en la apertura hacia el saber. Un nuevo vínculo, otro juego de presencias. El deseo de cultivar la relación con el saber. Una relación que traiga intensidad y sensibilidad, que contenga trayectoria vital, que acoja la vibración del cuerpo en su relación con lo conocido, y con lo desconocido. Lo que está por conocer. Un saber corporizado. Un saber sostenido en la inquietud y en el asombro. En este sentido, las actividades y las tareas, los proyectos y las propuestas vivifican procesos que recrean y encarnan aquello presentado o que se va presentando como posibilidad de aprendizaje.

Voy descubriendo, poco a poco, esa composición curricular con la que Inma va conformando su "puzzle". Hablo de composición curricular en distintos sentidos. Desde la perspectiva curricular integrada que pone en relación dos o más materias con la indagación de problemas e interrogantes reales. Y con los saberes y las inquietudes personales que tienen las propias criaturas. Lo hago también desde una perspectiva relacional, colocando el acento en la confianza y el reconocimiento del otro como alguien que "me" ayuda a ir más allá, a abrir mi imaginación del mundo, reelaborar la propia experiencia, acompañar la propia curiosidad. Lo hago, por último, desde una perspectiva organizacional que busca una coherencia y continuidad entre las propuestas que se realizan en el aula y una consonancia con el trabajo que se desarrolla en las otras aulas del mismo nivel y con los proyectos conjuntos de centro. Una composición curricular, entonces, que va trabándose a partir de los planes de trabajo, las tertulias literarias, los proyectos de trabajos, las salidas, los grupos interactivos, los trabajos voluntarios, las preguntas viajeras, la libreta de textos propios, la asamblea y, la preparación de celebraciones conjuntas como: el día de la paz, los carnavales, las fallas, las jornadas musicales, las jornadas literarias, las clases hermanadas...

Para Inma y sus compañeras de nivel, es muy importante que la perspectiva de los proyectos de trabajo impregne el hacer en el aula. Y por eso no ponen deberes, pero dan posibilidad ( $\mathrm{y}$ prioridad) a experiencias de aprendizaje en donde las criaturas se plantean interrogantes, hacen búsquedas, planifican, reflexionan, deciden, se ponen en juego para ir buscando sentido a lo que hacen... Y lo hacen dentro y fuera del aula. $Y$ lo hacen en relación entre lo que pasa en el aula y lo que les sucede fuera de ella. De entre las distintas propuestas del puzzle curricular, creo que vale la pena profundizar en dos de ellas. En parte porque a través de ellas se me han ido haciendo presentes las criaturas con sus inquietudes, con sus cualidades, con sus recursos. $Y$ en parte, porque es a partir de todo ello que en mí se han enriquecido también los diferentes aspectos de la vida cultural. 


\section{Los trabajos voluntarios}

Después de un tiempo de estar acompañando la vida del aula, me di cuenta que buscaba muchos momentos para asistir los jueves por la tarde. Era el día que se dedicaba a la exposición de los trabajos. Cada tarde de jueves había entre cuatro y ocho trabajos para exponer. Trabajos que eran voluntarios y que las criaturas, con la complicidad de la familia, iban haciendo sin prisas, sin presión y con la única finalidad de compartir con el resto de la clase algo de lo que habían creado, vivido, investigado, descubierto o experimentado.

Hay todo un ritual en este tiempo de exposiciones. Los pupitres en forma de U y delante, centrado, un pupitre para quien expone. Hay quien utiliza el micrófono inalámbrico de Inma porque la timidez todavía le ahoga la voz. También hay, quien le pide a Inma que se quede a su lado mientras expone porque se siente demasiado inseguro, todavía, para hablar ante los demás. Hay quien se desenvuelve muy bien, o a quien se le nota cómo gana confianza. Hay quien ha hecho varias exposiciones y quien hace la primera pasado el primer trimestre. No importa. Cuando comienza la exposición se hace un silencio grande. Quien expone procura hablar despacio, con tranquilidad, con confianza. Quienes escuchan prestan atención, guardan silencio, miran a quien habla, felicitan y agradecen el trabajo bien hecho. Al terminar la exposición, Inma hace una foto al autor o autora con su trabajo para componer, con ellas, un mural de los trabajos expuestos en el mes. En octubre se presentaron 22 trabajos.

Durante este curso he podido escuchar a Lara presentar su mini cuaderno de chistes. Chistes que ha ido recopilando y transcribiendo a mano. Algunos los ha acompañado con una ilustración. Nos contó cómo lo había hecho y luego leyó en voz alta algunos de los chistes. Aitor había inventado una historia "de miedo" y con Inma al lado la fue leyendo poco a poco. Yara y Lola presentaron un castillo medieval realizado con la ayuda del padre de Yara. La manualidad mostraba por delante el interior del castillo y por detrás los jardines del mismo. Recogieron información sobre la Edad Media y hablaron de cómo se vivía en esa época. Sergio toca la trompeta y un jueves trajo su trompeta y tocó una pieza. Luego explicó a la clase lo qué son los instrumentos de viento. Ana, había investigado sobre el universo en casa y construyó con ayuda de su padre el sistema solar. Se preparó pequeñas tarjetas con la información que había ido recogiendo para ayudarse en la exposición. Andrés preparó una conferencia sobre el plástico y el reciclaje con la ayuda de su abuela. Vicky, Ana y María se juntaron algunos ratos en el comedor para confeccionar un desplegable muy original sobre la fruta. Domi construyó un telescopio muy especial y Noah hizo el símbolo de la bandera pirata y lo regaló a la clase. Danna trajo material para hacer un reno navideño. A Ferran le gustan los jeroglíficos y se inventó un código con el que jugamos a construir palabras.

En este tiempo de exposiciones también se han traído cuadernos de dibujos, murales sobre animales exóticos o información interesante sobre alguna mascota. Bibi expuso la entrevista que le hizo a la cuidadora de los lémur en el Biopark cuando fue con su madre. También ha habido adivinanzas, trucos de magia, relatos de viajes, elementos de la naturaleza que se han recogido durante una excursión, experimentos con la luz y algunas representaciones de las constelaciones... Las niñas y los niños han ido tomado la iniciativa, han recopilado información, la han ordenado, y la han presentado. 
Durante su exposición han explicado y agradecido cuando alguien de la familia les ha ayudado. Es un tiempo enriquecedor para toda la clase en el que se fomentan ideas, se ayuda a atravesar el vértigo de mostrarse ante los demás y se ofrece la oportunidad de cultivar la escucha y el respeto.

\section{Preguntas viajeras}

Una preocupación viva en esta maestra es que las criaturas se hagan preguntas. Las preguntas invitan a pensar y a través de ellas, se van estableciendo múltiples relaciones con el saber. Esta propuesta de la preguntas viajeras es otra pieza del "puzzle" curricular que Inma viene planteando desde hace ya algunos años. En su trayectoria la propuesta ha ido tomando rumbos diversos. Se ha presentado de manera diferente, con variaciones. Pero, ¿por qué se llaman preguntas viajeras? Se llaman viajeras porque las preguntas se han ido formulando en el aula pero han de salir de ella para encontrar respuesta.

Este curso, la invitación ha sido el formular preguntas a partir del estudio de los cuadernos con los que trabajan las asignaturas de Ciencias Sociales y Ciencias de la Naturaleza. Formular preguntas a las que no han encontrado respuesta en el cuaderno de estudio o preguntas que se originan a partir del estudio. Es decir, preguntas que interrogan los enunciados, que profundizan algún concepto o idea, o que tratan de ampliar en algún aspecto o sentido el conocimiento que se les ofrece. “¿Cómo caen los asteroides a la Tierra?”, se pregunta Yara. O Noah que plantea: “¿quién le pone el nombre al sol?”. Las preguntas que se hacen les permite explorar de nuevo y desde sí, parte de la realidad social y natural que ha despertado su interés, su curiosidad. Se abre una brecha que permite habilitar procesos de singularización en relación con el saber. Que toca las sensibilidades y aviva la tensión entre lo dado como saber y la emergencia de un no-saber que lo acompaña; una tensión que moviliza la potencia del pensamiento/ creación. Que da cuenta de ese cuerpo vibrátil del que nos habla Suely Rolnik (2006) por el que nos dejamos atravesar, y alterar, poniendo en relación la realidad interna con el mundo externo y, desde donde buscamos un modo singular y propio de colocarnos ante lo otro y de actuar desde sí dejándonos afectar por la alteridad.

Las preguntas que van planteándose las recoge la maestra para ponerlas a circular en clase. Lee en voz alta la pregunta que alguien ha formulado y en el grupo aparecen voluntarios y voluntarias que deciden buscar la respuesta. A veces, para una pregunta se ofrecen muchas criaturas. Algo ha movido en ellas. Para otras preguntas, apenas una o dos la aceptan. Hay criaturas, como Ana, que aceptan muchas preguntas y otras que se arriesgan menos o que les cuesta arriesgarse. No hay obligación de hacerse cargo de ninguna pregunta, aunque Inma procura mediar un poco entre tanto desequilibrio. Procura dar medida al ímpetu de unos y a la indecisión de otros. Pero en el momento en que alguien se hace cargo de una pregunta, esta comienza su viaje. Sale del aula para instalarse en otros hogares. Hasta que un tiempo después, vuelve. Inma recupera poco a poco las preguntas y las respuestas. Las organiza. Para cada pregunta, la pregunta de alguien, una o varias respuestas propuestas por alguien, también. Preguntas y respuestas que tienen autoría y con las que elabora el cuadernillo trimestral que se presenta y circula en el aula, que hace las veces de material de consulta y de documentación. 
A la pregunta de Bibi: “¿por qué la Tierra se dice así, si la mayor parte es agua?”, se presentan voluntarias para buscar respuesta Ana, Vicky, Sergio y Teresa. Sus respuestas son:

- Ana: Antes la humanidad no podía ver la Tierra desde el espacio, y le pusieron ese nombre porque "Tierra" significa "suelo bajo los pies"

- Vicky responde con dos teorías y lanza un pregunta: $1^{a}$ Teoría: quiere decir "suelo bajo los pies". 2a Teoría: los nombres de los planetas vienen de los dioses griegos y romanos. En la mitología griega había una diosa llamada Gea (la madre de todo). Gea significa Tierra, y así la nombraron los romanos. ¿Con qué teoría te quedas?

- Sergio aclara: En realidad bajo el agua hay tierra, incluso montañas, por eso tal vez le dicen Tierra

- Teresa amplia la explicación: Conforme vemos la Tierra desde fuera, vemos más agua, pero bajo del agua hay tierra. Si contamos la de la superficie y la de bajo, hay más tierra que agua.

Cuando las niñas y los niños buscan respuestas a las preguntas formuladas, lo que buscan en realidad es acompañar la curiosidad de alguien y vivirse a sí mismos en esa vibración. Responden desde lo que ellas mismas son capaces de comprender y de explicar con sus propias palabras. No se trata de copiar definiciones sino de comprender lo que encontramos escrito, interpretarlo, darle un sentido propio para poder ofrecerlo al otro.

De los cuadernos de estudio sobre el cuerpo y la salud han salido también muchas preguntas curiosas. En algunas ocasiones, porque también puede ser así, la misma criatura que formula la pregunta se hace responsable de buscar la respuesta. En estos cuadernos aparecen preguntas exigentes, hay veces que los datos científicos parecen irreconciliables con lo que percibimos de nosotros mismos. Y una se tiene que asegurar de que son ciertos. “¿Es seguro que tenemos 206 huesos?”, pregunta Lola. Y Ana responde: "sí, seguro". Y Sergio añade: "sí, seguro tenemos 206 huesos porque una vez unos científicos a una persona le hicieron una fotografía de todo el esqueleto y contaron 206”. Ángel, aplicando la lógica elemental, piensa que de pequeños tenemos menos huesos pero prefiere asegurarse y pregunta: “¿Cuándo eres pequeño tendrás menos huesos que cuando eres grande, no?”. Días después, recibe respuestas:

- Andrés: "todo lo contrario. Los bebés tienen más de 300 huesos y después el número va bajando hasta quedarse en 206 que tenemos de adultos. Durante la infancia una parte de los huesos crecen divididos. El cráneo de un bebé está constituido por 29 huesos, que poco a poco van soldándose”.

- Ferran responde de manera general: "todas las personas nacemos con el mismo número de huesos".

- Ana insiste: "cuando somos pequeños tenemos 300 huesos, y cuando nos hacemos mayores se fusionan algunos huesos y llegamos a tener 206".

- Sergio concluye: "cuando eres pequeño los huesos son más pequeños" 
Para esta maestra cuidar la forma en que somos y estamos ante las criaturas, es lo que hace posible que estos prosperen en sus aprendizajes. En este sentido sugiere que vivificar el currículum, habitarlo, precisa de un cuidar la relación educativa para hacerla fructífera, porque desde ella se acompaña el crecimiento interior y relacional. Se precisan espacios de confianza para que la relación circule también entre las propias criaturas. En los que se pueda atender los ritmos diversos para facilitar que las criaturas entren en juego en primera persona en su relación con el saber. Sabe que una relación educativa fructífera despeja el camino a la enseñanza y el aprendizaje. Sin una buena relación educativa, escribe, "no hay nada fructífero que sea posible, y sé también que la relación educativa no surge solamente de estar juntos y de convivir en el aula. Decido poner en el centro la relación, porque es la mediación que me orienta en la gradación y la selección de los contenidos, las actividades más útiles y saludables, la evaluación de los aprendizajes, etc. La relación educativa es el puente que me ayuda a atravesar cansancios, dificultades, desacuerdos y desaciertos", (Inma Coscollá, 2016, p.59).

Hay un proceder en esta maestra, cuidadoso y amoroso, que confía y reconoce esa curiosidad rica e inteligente con la que las criaturas se relacionan con la realidad. Y tantean, exploran, elaboran hipótesis y hacen crecer sus inquietudes. Un proceder que requiere también una apuesta alta, atreverse a alterar, y a deambular, lo que viene definido como currículum. Alterar para hacer lugar a lo que no está prescrito pero tiene que ver con lo que nos está pasando. Deambular, dice Teresa Punta (2013), para que el curriculum no sea un elemento más del paisaje escolar al que se responde o ante el que se responde sin hacerlo pasar a través de sí. Sin habitarlo, sin vivirlo en primera persona. Sin dejarse tocar por quien se tiene delante y sin dejarse interpelar por lo nuevo que trae, por lo adecuado a cada situación. Vivificar el currículum, habitándolo, es un arte complicado que se va aprendiendo.

\section{Caminar volviéndose atenta}

¿Qué significa acompañar a niñas y niños que aprenden? Esta pregunta me llevó a la escuela, al aula de Inma. Me invitó a caminar, me puso en camino. Estando cerca de estas niñas y estos niños y de su maestra, me voy dando cuenta que acompañar requiere de un pensar sensible al otro. Es estar cerca del otro, de la otra, pero sobre todo supone dejarse afectar por su presencia. Y es este dejarse afectar lo que va abriendo ese espacio relacional que se sostiene en una amalgama de gestos. Hablo de gestos no de recursos, porque no son, o no solo son, "cosas que se saben hacer" (Cifali, 2005) sino actos que parten de alguien y que se van desplegando (Molina, Sierra y Sendra, 2016). La gestualidad, sugiere Emma Quiles-Fernández (2016), crea un espacio tácito, que acoge, nos reconforta o nos perturba, pero que nos hace presentes en la relación y nos pone en relación.

Acompañar a criaturas que aprenden implica también dejarse acompañar en este camino de ir haciéndose maestra, porque es un camino que tiene horizonte pero no final. Dejarse acompañar por otras compañeras, por las familias, por las propias criaturas. Acompañar puede decirse que es algo así como caminar en compañía, caminar junto al otro, con el otro. $\mathrm{Y}$ en ese caminar ir volviéndose atenta al camino, al otro y al propio caminar. Precisamente esto de ir volviéndose atenta es algo que 
percibo con mucha claridad en Inma, y es también algo que está muy presente en la vida que tiene este aula. En ese movimiento que trae quien la habita y en esa cadencia necesaria, que se va aprehendiendo, para ir acompasando el viaje.

Aprendo que acompañar a criaturas que aprenden tiene mucho que ver con saber estar cerca del comienzo (Mecenero, 2003), de lo que va naciendo, para sostenerlo, nutrirlo, para ayudar a crecer o a contener. Dando medida, exigencia y cuidado. Explorando un saber estar pausado ante el desasosiego. Acompañar a criaturas que aprenden a ratos exige hacer lugar a la tensión, la incomodidad y también al dolor. Porque saber lo que es bueno y lo que hace daño, lo que es necesario y adecuado o lo que no conviene en absoluto; no determina el modo en que nos comportamos. No siempre hacemos con los otros y lo otro en relación con este "saber", estas orientaciones de (y en) la relación. Un comentario inapropiado, una pelea, un grito, un empujón, un insulto, un engaño, son comportamientos que se suceden. Y que se suceden a diario. Con muy poca intensidad casi siempre, pero en ocasiones la intensidad se dispara. La experiencia de ser, saber y sentir son experiencias indisolubles y experiencias siempre en tensión con lo que vivimos en cada momento, y con cómo reaccionamos ante ello. Acompañar a las criaturas en su proceso de crecer, de llegar a ser, nos exige ser conscientes de estas tensiones que viven, que atraviesan y que se están sucediendo porque forman parte de ese experimentar el mundo. Es saber estar cerca del otro, de la otra en lo que trae en cada momento, no para sostener todo lo que trae pero sí para dar medida en las relaciones que va experimentando o generando con la alteridad.

Acompañar, crecer, enseñar, aprender parece que requiere más de atención que de intención. De una atención cuidadosa, amorosa, paciente, porque algo importante nos jugamos en ello: la apertura a un espacio existencial. Un espacio de libertad práctica que es nuestra alma, (Masschelein, 2008).

Son casi las cinco menos cuarto. Termina la jornada escolar. Las niñas y los niños van recogiendo con orden sus cosas. Inma confirma la hora mirando el reloj de la pared frontal del aula. Algunas criaturas ya tienen cargada la mochila pero se entretienen merodeando por el aula. Inma deja lo que está haciendo y camina sonriente hacia la puerta. Anna se le acerca y le da un abrazo. También María y Lola y Andrés. Miro a Inma. Ferran le está enseñando unos cromos, se sonríe y se despide de ella con un beso. Siguen Noah, Sergio, Teresa. Me cuesta un tiempo entender lo que está pasando porque la escena me descoloca y me exige atención y silencio. Las niñas y los niños se están despidiendo de su maestra. Para cada quién algo: una caricia, una sonrisa, un guiño, una palabra amable, un recordar algo para mañana, un buen deseo, un agradecimiento, un suspiro, un respiro...

Inma cuida este momento. Para ella y para las criaturas tiene valor y sentido. Es un acto de amor y de reconocimiento que da medida de la centralidad que la relación ocupa en el devenir cotidiano de este aula. Este gesto en el que nos despedimos del otro con quien se ha compartido tiempo de vida, de relación, de reflexión, de juego, de trabajo da cuenta de un sentido de la hospitalidad comedida, mesurada. Parece importante atender esta gestualidad mínima (Skliar, 2011) porque gesto y palabra, ejemplo y explicación, necesitan ir unidos en este acompañar a criaturas que aprenden. En un enseñar lo indecible (Le Breton, 2010). 


\section{Pasaje de deseo}

La experiencia de acompañar este tiempo a esta maestra y sus criaturas en el aula así como, la apuesta por cartografiar este acompañamiento siguiendo el hilo de la experiencia sensible, de la corporalidad, me ha ayudado a vivir y a pensar la escuela como un lugar para ser. Sobre todo como un lugar propicio para ir siendo, sabiendo que la propia escuela es un mundo, en un mundo donde el sentido de la Escuela se encuentra diluido y perdido, (Recalcati, 2016). El mundo de la escuela supone un espacio posible de exploración y de experimentación en el que las criaturas pueden descubrir las múltiples formas de vivir y de ser, que desde un punto de vista cultural e histórico, contiene la experiencia humana. No es el único espacio posible, pero sí un espacio necesario, un espacio público, en una sociedad cada vez más individualizada y desarticulada, más líquida (Bauman, 2005); y en un mundo cuyas ilusiones se generan y alimentan del discurso capitalista y neoliberal.

La escuela que he ido viviendo y descubriendo en este tiempo acompañando a la maestra, tiene mucho de ese movimiento alegre que trae la búsqueda, la creación, la pregunta. "Cómo nos miramos, cómo nos hablamos, ayudamos, qué hacemos, cómo distribuimos el tiempo, cómo procuramos que nos quepa mucho de lo que deseamos y creemos que podemos hacer, cómo vivimos con intensidad cada día, cómo aprendemos, cómo nos queremos", Inma Coscollá (2016, p.8). Preguntas con vida que se mantienen abiertas, y se avivan cada vez, para que aquello que viene dado e impuesto no ahogue lo que está por nacer, lo que necesita tener lugar, lo que precisa ser atendido. Y la escuela se va armando con una atmósfera envolvente que reconoce la necesidad de saberse cerca del otro, en relación con el otro y por ello cuida la posibilidad del encuentro. Cuida la posibilidad de la presencia del otro; la belleza del espacio que se comparte; las palabras que acompañan el gesto; el gesto que nace de la atención al otro.

La experiencia sensible de esta escuela se me presenta como pasaje de deseo que me ayuda a profundizar el sentido de lo educativo. Poner en el centro la relación exige a la escuela una apertura que, en el proceder normativo y administrativo, siempre queda zanjada porque ya se "nos" dice quién es el otro, qué tiene que ocurrir en ese encuentro, qué se ha de esperar y que se ha de conseguir. Poner en el centro la relación supone aprender a sostener la experiencia educativa sobre la práctica del cuidado. No como un desafío profesional sino como exigencia de poner en juego lo más humano: el deseo profundo de encontrarse con el otro. Sosteniendo el encuentro magistral que hace posible ampliar la imaginación del mundo, que hace existir mundos nuevos.

\section{Referências}

BÁRCENA, F. y MÈLICH, J.C. El aprendizaje simbólico del cuerpo. Revista Complutense de Educación, v.11, n.2, 59-81, 2000.

BÁRCENA, F.. Una pedagogía de la presencia. Crítica filosófica de la impostura pedagógica. Teoría de la Educación. Revista Interuniversitaria, 24, 25-57, 2012.

BAUMAN, Z. Amor líquido. Acerca de la fragilidad de los vínculos humanos. México. Fondo de Cultura Económica. 2005.

CIFALI, M. Enfoque clínico, formación y escritura. En L. Paquay, M. Altet, È. Charlier y Ph. Perrenoud (Coords). La formación profesional del maestro. Estrategias y competencias (170196). México: Fondo de Cultura Económica. 2005. 
CONTRERAS, J. Personalizar la relación: aperturas pedagógicas para personalizar la enseñanza. Revista del Fórum Europeo de Administradores de la Educación, v.15, n. 4, 17-24. 2007.

COSCOLLÀ, I. Pràctiques que ajuden a construir la relació educativa. Guix. Elements d'Acció Educativa, 421, 55-59. 2016.

COSCOLLÀ, I. Cuidar los vínculos entre criaturas. Cuadernos de Pedagogía, 467, 8. 2016.

COSCOLLÀ, I. Saber es un placer. Cuadernos de Pedagogía, 470, 8. 2016.

COSCOLLÀ, I. Quién es el sistema educativo. Cuadernos de Pedagogía, 471, 8. 2016.

DÍEZ, M. C. Los pendientes de la maestra. O cómo piensa una maestra en los niños, las escuelas, las familias y la sociedad de hoy. Barcelona: Graó. 2011.

DUARTE, C. y Villar, A. El cuerpo entramado: hacia una poética de las afecciones. El tolde de Astier, 13, 82-89. 2016.

LE BRETON, D. Cuerpo sensible. Santiago de Chile. Metales Pesados. 2010.

LÓPEZ, A. Un lugar para ser. En J. Contreras (coord.). Enseñar tejiendo relaciones (55-58). Madrid. Morata. 2017.

MASSCHELEIN, J. Pongámonos en marcha. En J. Masschelein y M. Simons (eds). Mensajes educativos desde tierra de nadie. (21-30). Barcelona. Laertes. 2008.

MECENERO, C. Cerca del comienzo. DUODA Revista d'Estudis Feministes, 25, 103-109. 2003.

MÈLICH, J.C. La persistencia de la metamorfosis. Ensayo de una antropología pedagógica de la finitud. Revista Educación y Pedagogía, v. XVI, n. 42, 11-27. 2005.

MOLINA, M.D.; Sierra, J.E. y Sendra, C. Saberes docentes y educación infantil. Notas pedagógicas para la formación inicial. Revista Iberoamericana de Educación, vol. 72, 65-84. 2016.

NANCY, J-L. 58 indicios sobre el cuerpo: Extensión del alma. Buenos Aires. La Cebra. 2006.

NODDINGS, N. Identifying and responding to needs in education. Cambrige Journal of Education, vol. 35, no 2, 147-159. 2005.

PUNTA, T. Señales de vida. Una bitácora de escuela. Buenos Aires. Lugar Editorial. 2013.

QUILES-FERNÁNDEZ, E. Cuidar la relación: el sentido de la experiencia educativa. Una investigación narrativa. Tesis Doctoral presentada en la Universitat de Barcelona (inédita). 2016.

RECALCATI, M. La hora de clase. Por una erótica de la enseñanza. Barcelona. Anagrama. 2016.

RITSCHER, P. ¿Qué haremos cuando seamos pequeños? Barcelona. Octaedro-Rosa Sensat. 2002.

ROLNIK, S. Sostenerse en la fragilidad, más allá de toda erudición. Campo Grupal, 79, 2-5. 2006.

SKLIAR, C. Diez escenas educativas para narrar lo pedagógico entre lo filosófico y lo literario. Revista Plumilla Educativa, 8, 1-19.2011.

VAN MANEN, M. El tono en la enseñanza. El lenguaje de la pedagogía. Barcelona. Paidós. 2004. 


\section{Notas}

${ }^{1}$ Bebe es una cantante cuya música se sitúa dentro de la canción protesta con mirada feminista.

${ }^{2}$ Esta escena que da inicio a este estudio con una maestra de Primaria está vinculada al trabajo de indagación realizado en estos dos proyectos de investigación: (GV/2014/058) "Prácticas y saberes de la relación educativa y su implicación en la formación inicial del profesorado. Estudio narrativo sobre experiencias docentes en Educación Primaria”. Financiado por la Conselleria d'Educació, Invesigació, Cultura i Esport de la Generalitat Valencia. Dirigido por Dra. Ma Dolores Molina Galvañ. (EDU2016-77576-P): "Relaciones educativas y creación del curriculum: entre la experiencia escolar y la formación inicial del profesorado. Indagaciones narrativas". Financiado por la Agencia Estatal de Investigación (AEI) del Ministerio de Economía, Industria y Competitividad y el Fondo Europeo de Desarrollo Regional (FEDER). Dirigido por Dr. José Contreras Domingo.

${ }^{3}$ Durante el segundo semestre del curso 2014-2015 y durante todo el curso 2015-2016, he acompañado a una maestra (Inma) y sus criaturas en la vida cotidiana del aula y la escuela. Una escuela pública en un pueblo del sur de Valencia cercano a la ciudad. Y durante este período de observación he vivido la actividad educativa en los dos cursos del segundo ciclo de Primaria, que comprende a niños y niñas entre 8-10 años.

${ }^{4}$ Escribe Teresa Punta (2013, p.52): "Si en la escuela no se da el encuentro no hay escuela. El encuentro el registro de un "otro", es el registro de lo no común (lo otro), entonces... el registro de lo otro es el principio del encuentro y el principio del armado del común. Entonces, ¿lo que arma común es el registro de lo otro?

${ }^{5}$ Asunción López (2016) reflexiona en relación a los edificios escolares: "A menudo me pregunto si los responsables de planificar y realizar los edificios escolares tienen criaturas propias o cercanas. Entrar en uno de estos edificios es algunas veces muy decepcionante. Y no por la ausencia de estética -que también-, sino por la ausencia de vida. No parecen lugares habitables, lugares que den cobijo. [...] Un espacio, una casa o una escuela son reflejo de estilos de vida. Ese es el valor simbólico del espacio"

${ }^{6}$ La regulación actual exige que las clases sean de 45 minutos y a cada asignatura le corresponde un total de minutos semanales.

* Professora doutora do Dpto. de Didática e Organização Escolar da Universidad de Valencia, Valencia, Espanha.

\section{Correspondência}

Maria Dolores Molina Galvañ - Facultat de Magisteri - Universitat de València. Av. Tarongers, 4. CEP: 46022. Valencia, España.

E-mail: m.dolores.molina@uv.es

Recebido em 04 de janeiro de 2018

Aprovado em 10 de abril de 2018 
